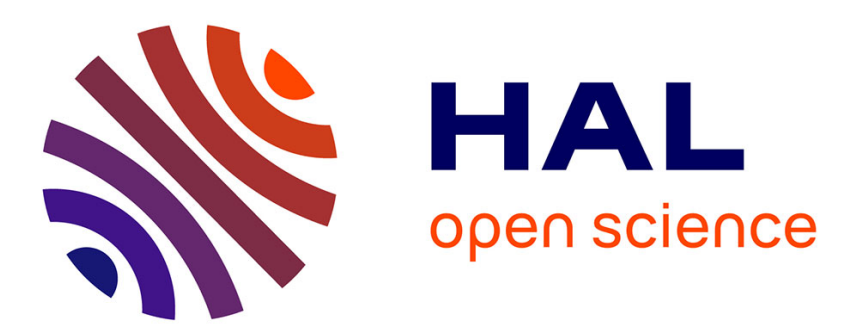

\title{
Neel Effect current sensor featuring double core toroidal topology
}

Eric Vourc'H, Yu Wang, Pierre-Yves Joubert, André Couderette, Lionel Cima

\section{To cite this version:}

Eric Vourc'H, Yu Wang, Pierre-Yves Joubert, André Couderette, Lionel Cima. Neel Effect current sensor featuring double core toroidal topology. Electronics Letters, 2012, 48 (22), pp.1412 - 1414. 10.1049/el.2012.1217 . hal-00825808

\section{HAL Id: hal-00825808 https://hal.science/hal-00825808}

Submitted on 24 May 2013

HAL is a multi-disciplinary open access archive for the deposit and dissemination of scientific research documents, whether they are published or not. The documents may come from teaching and research institutions in France or abroad, or from public or private research centers.
L'archive ouverte pluridisciplinaire HAL, est destinée au dépôt et à la diffusion de documents scientifiques de niveau recherche, publiés ou non, émanant des établissements d'enseignement et de recherche français ou étrangers, des laboratoires publics ou privés. 


\section{Neel Effect current sensor featuring a double core toroidal topology}

\author{
E. Vourc'h, Y. Wang, P.Y. Joubert, A. Couderette, L. Cima
}

A Neel Effect® current sensor featuring a double toroidal core is proposed. The measurement relies on the application of a harmonic excitation to the magnetic core and on the sensing of the magnetic flux density variations in the presence of a current to measure. The principle of a device designed so as to perform both those operations by means of the same winding is presented and validated experimentally. The measurement of DC currents is carried out over the [-200 A $200 \mathrm{~A}]$ range under different excitation conditions.

Introduction: There exist many current sensor technologies such as shunt, Hall current sensors, fluxgates, current transformers, Rogowski coils etc. $[1,2]$. They differentiate from each other by their ability to measure AC or DC signals and by their performances in terms of dynamic range, sensitivity, accuracy, size, flexibility, cost etc. Neel Effect current sensors which have recently been proposed [3,4], rely on a principle almost similar to that of a fluxgate. Their originality lies in the characteristics of the magnetic transducer, the non linearity behavior without saturation of which enables the measurement of high currents to be performed. Sensors based on the Neel Effect principle are being developed using superparamagnetic (SPM) nanostructured materials. Thus, Neel Effect sensors belong to the magnetic field sensors category. On the one hand, a harmonic magnetic field excitation is applied to the transducer via a winding fed by a sinusoidal current and on the other hand, the electromotive force (EMF) due to the magnetic flux density variations is sensed, also by a winding. In the presence of a current to measure, assumed to be continuous or slowly variable with respect to the excitation, a magnetic bias point is superposed to the magnetic excitation of the magnetic core, which results in a modification of the sensed EMF. The measurement of the EMF, and in particular that of the component at the second order harmonic of the excitation frequency, enables the current to be determined [4]. Furthermore, it is to be noted that the core of the sensor being a plastic matrix loaded with superparamagnetic particles, flexible and consequently easy to install devices can be designed. In addition, SPM materials being completely remanence free, this avoids the problems of magnetic offset which sensors implementing ferromagnetic materials such as Hall probes are confronted with [2]

In this letter we present a Neel Effect current sensor featuring a double toroidal core and a winding performing both the excitation and the sensing operations

Sensor topology: The considered sensor (Fig. 1) is made up of two SPM cores which both feature a homogeneous winding. Those windings are wound in opposite directions and connected in series. The resulting coil is used for both the excitation of the SPM material and for the measurement of the current $I_{m}$ crossing the primary conductor surrounded by the cores. The excitation current is applied via two sinusoidal voltages sources at the same frequency $f_{e x}$ and featuring the same amplitude but opposite signs (denoted $\pm v(t)$ in Fig. 1) applied at both ends of the coil. With regards to the measurement of the EMF due to enable the determination of $I_{m}$, it is measured at the middle $\mathrm{M}$ of the winding.

Analytical model: An analytical model for Neel Effect sensors has been developed in [4]. According to this model and assuming that the magnetic flux density is homogeneous on the surface of the windings, the EMF sensed by a torus reads:

$$
\begin{aligned}
e_{i}(t) \cong-N S \mu_{0} \mu_{r}\left(H_{m}\right) \omega_{e x} h_{e x} & \cos \left(\omega_{e x} t\right) \\
& \left.-\left.N S \mu_{0} \frac{\partial \mu_{r}}{\partial H}\right|_{H_{m}} \frac{\omega_{e x}}{2} h_{e x}{ }^{2} \sin \left(2 \omega_{e x} t\right)\right)
\end{aligned}
$$

where $i \in\{1,2\}$ denotes the considered torus, where $\mu_{0}$ is the magnetic permeability in a vacuum, $\mu_{r}$ is the relative magnetic permeability of the SPM material, $h_{e x}$ is the amplitude of the excitation magnetic field, $H_{m}$ is the amplitude of the magnetic field created by the current to measure $I_{m}, S$ is the surface of the cross section of the windings, $N$ is the number of turns on a torus and $\omega_{e x}$ is the angular excitation frequency.

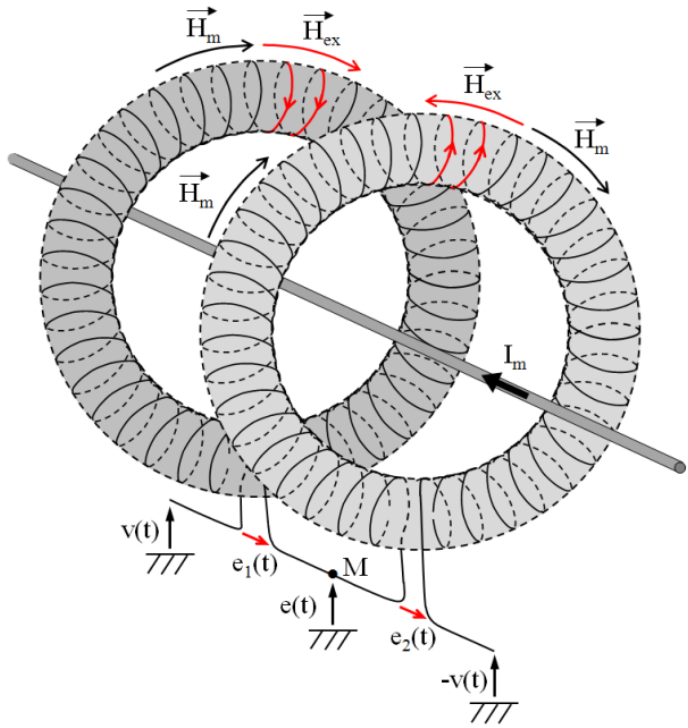

Fig. 1 Neel Effect sensor topology implementing two cores featuring homogeneous windings wound in opposite directions and connected in series.

Considering the current and voltage notation conventions used in Fig. 2, one has for the sensor output signal

$$
e(t)=\frac{1}{2}\left(e_{1}(t)-e_{2}(t)\right)
$$

$e_{i}(t)$ feature components at $\omega_{e x}$ and at $2 \omega_{e x}$. According to (1), their amplitudes are proportional to $\left.\frac{\partial B}{\partial H}\right|_{H_{m}}=\mu_{0} \mu_{r}\left(H_{m}\right)$ and $\left.\frac{\partial^{2} B}{\partial H^{2}}\right|_{H_{m}}=$ $\left.\mu_{0} \frac{\partial \mu_{r}}{\partial H}\right|_{H_{m}}$, which are the first and the second derivatives of the magnetization curve of the SPM material at the point $H_{m}$ respectively. Since $\frac{\partial B}{\partial H}$ is an even and $\frac{\partial^{2} \mathrm{~B}}{\partial \mathrm{H}^{2}}$ an odd function [4], given the sensed magnetic field components directions (Fig. 1), the components of $e_{1}(t)$ and $-e_{2}(t)$ at $\omega_{e x}$ cancel each other out and the sensed signal is

$$
e(t)=-\left.N S \mu_{0} \frac{\partial \mu_{r}}{\partial H}\right|_{H_{m}} \frac{\omega_{e x}}{2} h_{e x}^{2} \sin \left(2 \omega_{e x} t\right)
$$

Since this signal is proportional to $\left.\frac{\partial^{2} B}{\partial H^{2}}\right|_{H_{m}}$, which is an odd function monotonous over a large range, the sensor topology lets the measurement of high currents without sign ambiguity to be envisaged (the latter range could be in the order of tens, hundreds or thousands of Amps, depending on the used SPM material). Moreover, the fact that the sensor topology enables the cancellation of the first harmonic component makes the detection of the second harmonic component easier. Indeed the amplitude of the latter component is much smaller than that of the first one.

Experimental validation: A Neel Effect sensor implementing homogeneously wound toroidal cores of $15 \mathrm{~mm}$ and $30 \mathrm{~mm}$ inner and outer radii respectively and featuring 1400 turns each was characterized. The $\pm \mathrm{v}(\mathrm{t})$ harmonic excitation signals were supplied by means of synchronized voltage generators. The sensor output EMF was measured at point $\mathrm{M}$ by means of an electrical spectrum analyzer. With regards to the DC current to measure, it was provided by a [0 $35 \mathrm{~A}]$ source connected to a primary conductor, the cable of which featured 20 turns wound inside the sensor so as to enable the characterization over the [-700 A $700 \mathrm{~A}]$ range.

The characterization was performed at several excitation frequencies $(10,20,30,40$ and $50 \mathrm{kHz})$ and for different excitation current amplitudes $(50,60,70,80$ et $90 \mathrm{~mA}$ rms $)$. The measured current range was [-200 A 200 A]. Fig. 2 provides with the amplitude of the EMF component at the second harmonic of the excitation frequency, the latter being fixed at $10 \mathrm{kHz}$. As expected [4] the measured signal follows an odd function, the amplitude of which increases as $I_{e x}$ increases. In Fig. 3, measurements performed at different excitation frequencies for $I_{e x}(\mathrm{rms})$ fixed at $60 \mathrm{~mA}$ are reported, which show than the measured signal increases with the frequency which is consistent with theory. The 
sensor that was used enables currents to be measured over the [-150 A $150 \mathrm{~A}]$ range as the characteristic is monotonous over this range.

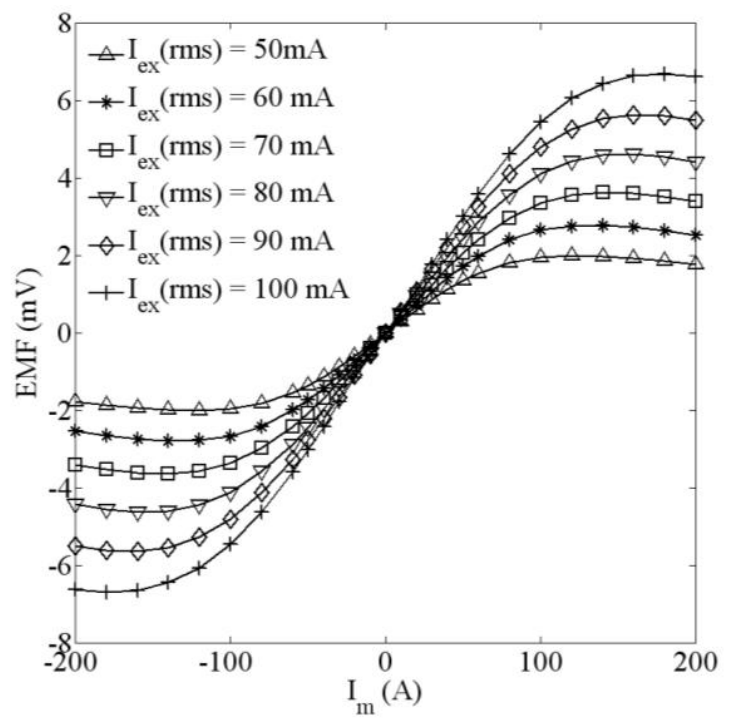

Fig. 2 Second harmonic component of the EMF at the output of the toroidal Neel Effect sensor measured for a $10 \mathrm{kHz}$ excitation frequency and for different amplitudes of the excitation current.

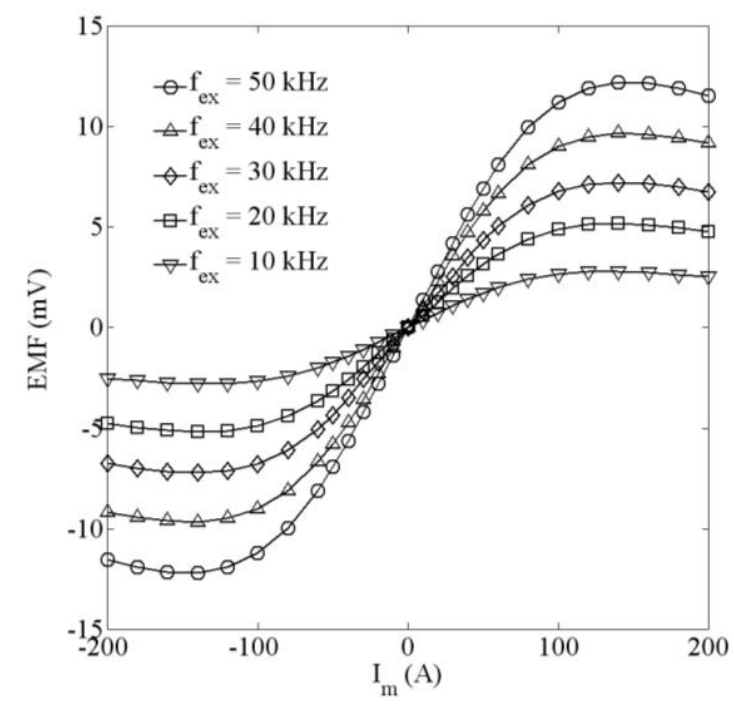

Fig. 3 Second harmonic component of the EMF at the output of the toroidal SPM sensor measured for a $60 \mathrm{~mA}$ rms excitation current and for different excitation frequencies.

Conclusion: A Neel Effect current sensor featuring a double core toroidal topology is proposed and demonstrated for the first time. Experimental characterizations of a device are carried out under different sensor excitation conditions (amplitude and frequency) the results of which are consistent with theory. The device enables DC currents to be measured over the [150 A $150 \mathrm{~A}]$ range.

Note: Neel Effect is a trade mark and a patented technology that belongs to Neelogy SA.

E. Vourc'h (SATIE, ENS Cachan, CNRS, UniverSud, 61 Av. du Président Wilson, 94230 Cachan)

E-mail: eric.vourch@satie.ens-cachan.fr

P. Y. Joubert (IEF, Université de Paris-Sud, CNRS UMR 8026, Centre Scientifique d'Orsay, Bât. 220, F-91405 Orsay)

H. Couderette and L. Cima (Neelogy S.A. 191, Avenue Aristide Briand 94230 Cachan France)

\section{References}

1 Ziegler, S., Woodward, R.C., Iu, H.H.C., Borle, L.J.: 'Current Sensing Techniques: A Review', IEEE Sensors Journal, 2009, 9, (4), pp. 354-376

2 Ripka, P., 'Electric current sensors: a review', Meas. Sci. Technol., 2010, 21112001

3 Lenglet L 2007 Current \& magnetic field sensors, control method \& magnetic core for said sensors, Billanco Patent WO2007042646 (A1).

4 E. Vourc'h, P.-Y. Joubert, L. Cima Analytical and numerical analyses of a current sensor using non linear effects in a flexible magnetic transducer. Progress In Electromagnetics Research Journal, PIER 99, 323-338, 2009 